\title{
How persistence paid off
}

\section{The struggle, delusion and arrogance of the character who found Java Man.}

\author{
The Man Who Found the Missing \\ Link: Eugene Dubois and His \\ Lifelong Quest to Prove Darwin \\ Right/The Extraordinary Life of \\ Eugene Dubois \\ by Pat Shipman \\ Simon \& Schuster/Weidenfeld \& Nicolson: \\ 2001. 514 pp. $\$ 28 / £ 25$
}

\section{Douglas Palmer}

In her latest book, science writer and anthropologist Pat Shipman gives us a blow-byblow account of the life of Eugène Dubois, the Dutch physician and anatomist who in 1892 discovered 'Java Man', Pithecanthropus erectus, now known as Homo erectus. Shipman's account of Dubois' story is fascinating; much of it is set in an exotic location, and it is important for the insights it gives into the development of anthropology and the study of human evolution.

Dubois' long life started in 1858, the year before the publication of Charles Darwin's On the Origin of Species and five years before the first formal recognition of an extinct human species, Homo neanderthalensis, by William King in 1863. Dubois died in December 1940, the year German troops occupied the Netherlands. He was still fighting his corner, protesting about the paper by Ralph von Koenigswald and Franz Weidenreich in Nature (144, 926-929; 1939), which suggested that Pithecanthropus and Sinanthropus were two representatives of the same prehominid stage.

The story of why Dubois gave up a promising academic career at the University of Amsterdam, and dragged his family all the way to the Dutch East Indies in search of the so-called 'missing link' certainly has its own attraction. He had been inspired by Alfred Wallace's writings on Java's indigenous animals and plants and by Ernst Haeckel's theory - based on the belief that the Indonesian orang-utan was most closely related to humans - that humankind originated in Southeast Asia. After several fruitless years, Dubois found what he was looking for - the result of astonishing luck and sheer persistence. The years of struggle to get 'his' find acknowledged and recognized by other scientists is also an extraordinary story of struggle, bitter disappointment and delusion, combined with peculiar arrogance.

The ultimate pathos and tragedy of Dubois' story is painfully well portrayed by Shipman. By the time his find was accepted as a valid taxon, the world had moved on and Dubois' Java Man had been overshadowed by the newer and more spectacular finds of Sinanthropus, or 'Peking Man', now also

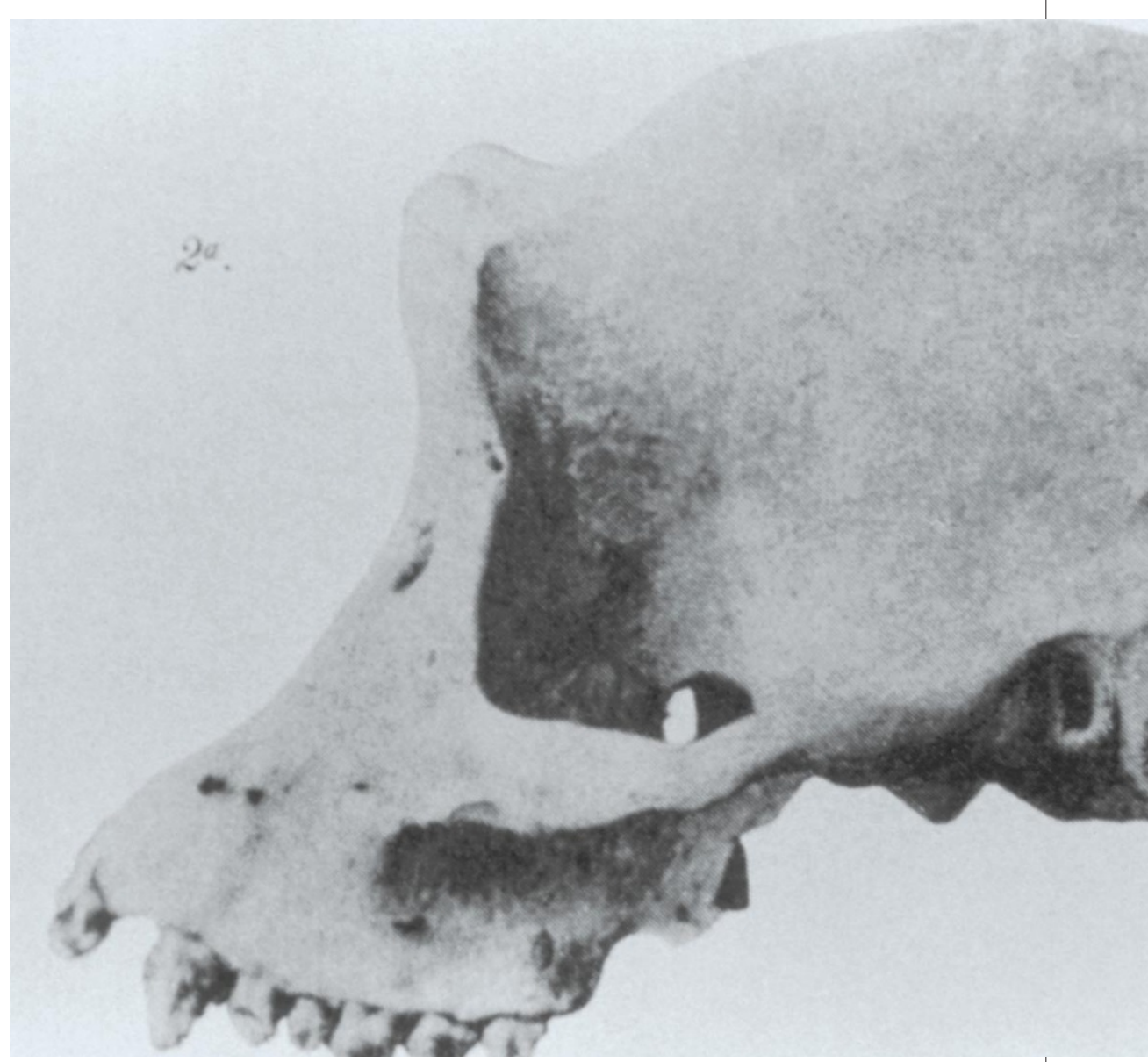

Object of derision: Dubois' drawing of the skull of his Pithecanthropus erectus.

regarded as Homo erectus. Nevertheless, as Shipman demonstrates, Dubois made significant contributions in other areas of anthropology, especially in his studies of cephalization - the evolution of the head and brain — and the morphometrics of brain and body size.

Shipman is at her most successful when quoting from Dubois' surviving letters and journals. There is, however, a certain amount of reconstructed dialogue and inner monologue of the following sort: "There, Dubois thinks as he pens the last lines, I have said it. I have stated my credo, my opinions, and it remains for the world to judge who is right. But it is I who will be remembered as the man who found the missing link." I found this tedious at times, even if there is good evidence for its validity, but other readers may be more tolerant.

Father J. J. A. Bernsen, a Jesuit priest, was Dubois' assistant in 1930-32, and Shipman has used his diaries, in which "many conversations with Dubois are recorded apparently verbatim". The hapless Father Bernsen spent two years cataloguing Dubois' collection of

^ ๔ 2001 Macmillan Magazines Ltd more than 10,400 mammal bones from the Trinil site where P. erectus had been found and hoped for some glimmer of recognition from Dubois. Bernsen even found eight more fragments of P. erectus bones that had been overlooked, but he got no thanks from Dubois. Quite the reverse - his find showed that one of Dubois' key points, that all the hominid bones at Trinil came from the same individual, was wrong. Dubois bullied Bernsen and plotted to get him removed. Poor Bernsen was taken ill and died of abdominal bleeding, unthanked and unacknowledged by Dubois, who constantly complained of how poorly others treated him.

Shipman ends Dubois' story thus: "he left behind many enemies ... his story became notorious, told and mistold many times until it reached mythic proportions. It is now time for the truth, and I have told it." But although Shipman does set the record straight, and the often-prolonged traipsing through daffodil-filled fields of dialogue might well capture the spirit of the moment, can it be 'the truth'? If, however, she means the more problematic 'truth' about Dubois' 
unpleasant persona, then I agree. It must often have been difficult to write a biography whose hero turns out to have been quite a monster, however fascinating.

Douglas Palmer is at 31 Mawson Road, Cambridge CB1 2DZ, UK.

\section{Slaves to logic}

\section{The Universal Computer: The} Road from Leibniz to Turing

W. W. Norton: 2000.257 pp. $\$ 26.95, £ 18.95$

Computers Ltd: What They

Really Can't Do

by David Harel

Oxford University Press: 2000. 214 pp. $\mathfrak{1} 14.99, \$ 25$

\section{John Naughton}

John Maynard Keynes once observed that "practical men ... are usually the slaves of some defunct economist", although this may be regarded as special pleading from a practitioner of the "dismal science" - as Thomas Carlyle described economics. by Martin Davis

Nowadays everyone - or at any rate everyone who uses even a word-processor - is a slave of a defunct logician.

For computers are essentially logical engines rather than arithmetic calculators. This was Alan Turing's great insight, but it was in fact the culmination (or even a logical conclusion?) of a continuous stream of thought stretching back to Gottfried Leibniz. He not only built one of the earliest mechanical calculators, but also dreamed - according to Martin Davis — of finding "a special alphabet whose elements represented not sounds but concepts. A language based on such an alphabet should make it possible to determine by symbolic calculation which sentences written in the language were true and what logical relationships existed between them."

Davis's book is a charming unravelling of the intellectual thread that links Leibniz to Turing. The journey takes him first to the work of George Boole, who turned logic into algebra (and made one and one equal one, to the delight of generations of schoolboys). Then he surveys the despairing life of Gottlob Frege, who provided the first fully developed system of logic that encompassed

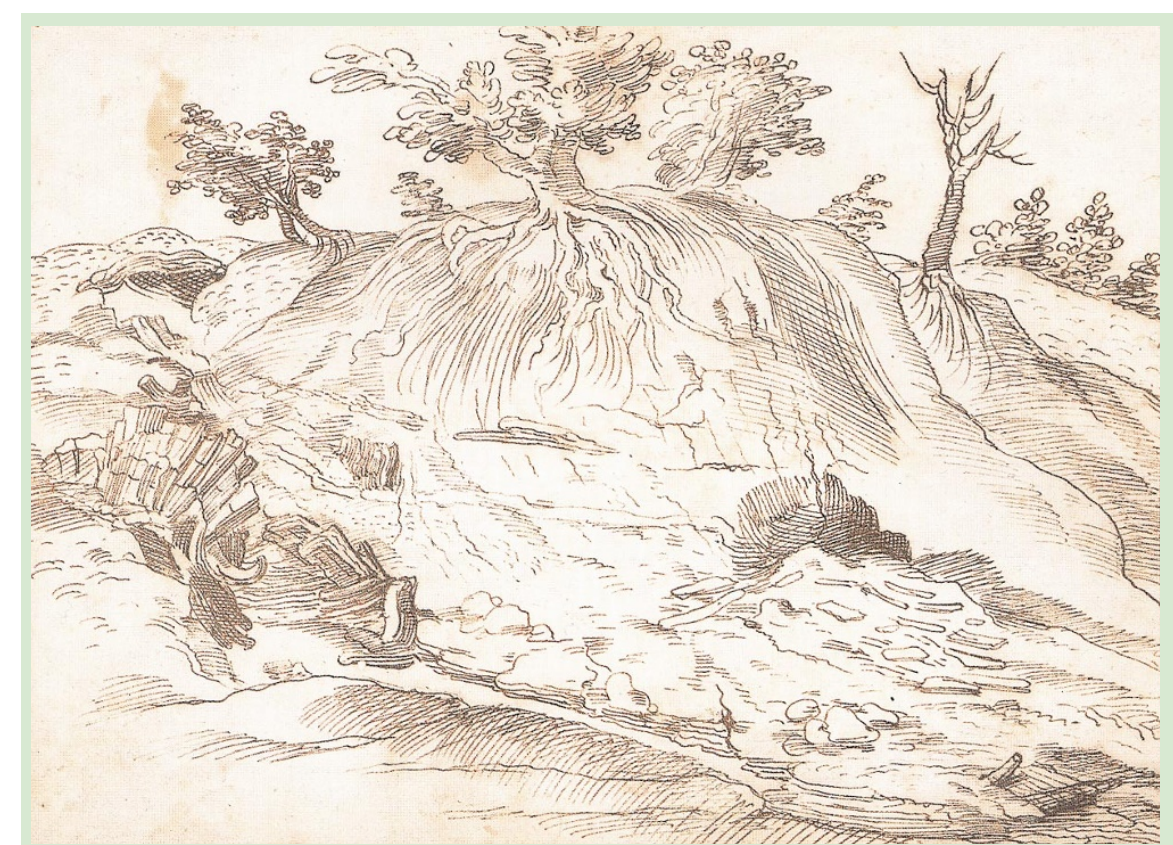

\section{Preserved for posterity}

A view of Italian fossil wood deposits (above) and a specimen of baked lignitic clay, from Fossil Woods and Other Geological Specimens by Andrew C. Scott and David Freedberg (Harvey Miller,

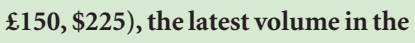
catalogue of the seventeenthcentury Paper Museum of Cassiano dal Pozzo. all of the deductive reasoning in ordinary mathematics, and yet had his life's work destroyed by a letter from Bertrand Russell pointing out an error in one of his fundamental assumptions.

Then there is Georg Cantor, who tried to create a coherent mathematical theory of the infinite. After him comes David Hilbert, who reduced the consistency of euclidean geometry to that of arithmetic, but left to others the problem of establishing the consistency of arithmetic.

After Hilbert, the baton passed to Kurt Gödel, who showed not only that there was a meaningful notion of mathematical truth, but also that it extends beyond what can be proved in any given formal system. Which brings us to Turing, who conceived of the allpurpose computer - the celebrated but infinitely tedious 'Turing machine' with its endless tape and relentless logic.

The task of hacking a readable path through the dense thickets of symbolic logic is not for the faint-hearted. It requires the inner confidence of the real expert - the chutzpah that enables a teacher to dispense with $95 \%$ of the detail and focus on the 5\% that really matters. The Universal Computer reeks of that kind of confidence, and as a result succeeds admirably in conveying the broad sweep of its subject over three centuries. And it breaks with convention by dwelling not only on the intellects but also on the personalities of its heroes. Frege, for example, may have been a saint in intellectual terms, but he was clearly a monster in the flesh. Gödel was a tortured soul whose mental stability became exceedingly fragile towards the end of his life. And even Turing was not without his daemons - although they may have had more to do with sexuality than mathematics. The reader is left with the feeling that while one clearly has to be very clever to make serious contributions to symbolic logic, one might have to be very peculiar to want to.

The fact that computers are logical engines, together with contemporary hype about Moore's law (which states that computing power doubles every 18 months), may have given rise to the popular fantasy that there are no limits to what one can achieve with software and the right hardware. If anyone does indeed harbour such illusions, then David Harel's book should be an excellent antidote. Its purpose is to explain why and how certain kinds of problems are not — and cannot be — solvable by computation.

Some of his material is adapted from an earlier, more technical exposition (Algorithmics: The Spirit of Computation, Addison Wesley, 1987), which likewise expounded what Harel calls the "bad news" about computing. Computers Ltd is crisply written for a popular audience and provides an excellent overview of the nature of algorithms and their 